\title{
The physical-chemical properties of substance of the bright fireball EN171101 Turyi Remety
}

\author{
Klim Churyumov ${ }^{1}$, Rudolf Belevtsev ${ }^{2}$, Emlen Sobotovich ${ }^{2}$, \\ Svitlana Spivak ${ }^{2}$ and Tetyana Churyumova ${ }^{3}$ \\ ${ }^{1}$ Astronomical Observatory of Kyiv Shevchenko National University \\ email: klimchur@ukr.net \\ ${ }^{2}$ Institute of of environmental geochemistry of NAS and MES of Ukraine ${ }^{3}$ Kyiv Shevchenko \\ National University
}

\begin{abstract}
In 2007-2011 searches were conducted for mineralogical and geochemical studies of the soil in the region of fall down of a bright fireball EN171101 "Turyi Remety" matter in Perechyn district of Transcarpathian. In the assumed location of the fall of a meteorite material for analysis was taken from the bottom of streams of Transcarpathian Mountains. In this matter we have been found numerous small magnetic spheres (microspherul) and fused segments, which have enough large sizes - up to $5 \mathrm{~mm}$ in diameter, which probably are fragments of the Turyi Remety meteoroid. One of the known signs of fireballs are sand-sized magnetic balls (by diameter 0.1-1.0 $\mathrm{mm}$ ), which are often found in the magnetic concentrate fraction. This small balls, together with fragments of fused iotsit $(\mathrm{FeO})$ are formed during the ablation of the meteoroid, and their sizes decreases during the motion of the meteoroid in the Earths atmosphere. From the east to the west, the radius of the balls in the study area decreased from an average of 0.7-0.5 mm to 0.1-0.3 $\mathrm{mm}$. The sizes of such balls, as glowing molten particles of the meteoroid, are in good agreement with calculations based on the energy loss of the Turyi Remety meteoroid. This confirms the cosmic origin of these found small balls. Pre-calculated physical parameters of the Turyi Remety meteoroid are the velocity, mass, kinetic energy, the resistance force during ablation, the average fireball particle radius along trajectory path of a meteoroid fragments depending from the mass and size. Rapid mass loss of the meteoroid in more than 10 times, stronger, shorter ablation and damping fireball at the high altitude say about instability and the participation of the meteoroid gas in ablation. Perhaps the presence of ice, and other fireball gases in the meteoroid composition shows that its composition was close to comet one or to a chondrite with ice (gas hydrates). Especially likely gaseous hydrates of heavy gases such as $\mathrm{CO} 2, \mathrm{H} 2 \mathrm{~S}$, hydrocarbons (propane, butane, etc.).
\end{abstract}

